\title{
Enthalpy relaxation studies in polymethyl methacrylate networks with different crosslinking degrees
}

\author{
N.M. Alves ${ }^{\mathrm{a}, \mathrm{b}}$, J.L. Gómez Ribelles ${ }^{\mathrm{c}}$, J.F. Mano ${ }^{\mathrm{a}, \mathrm{b}, *}$ \\ ${ }^{a}$ Polymer Engineering Department, University of Minho, Campus of Azurém, 4800-058 Guimarães, Portugal \\ b3B's Research Group-Biomaterials, Biodegradables and Biomimetics, University of Minho, 4710-057 Braga, Portugal \\ ${ }^{c}$ Center for Biomaterials and Department of Applied Thermodynamics, Universidad Politécnica de Valencia, P.O. Box 22012, E-46071 Valencia, Spain
}

Received 29 July 2004; received in revised form 21 October 2004; accepted 8 November 2004

Available online 26 November 2004

\begin{abstract}
Structural relaxation of PMMA networks with distinct crosslink density has been studied by differential scanning calorimetry (DSC). The crosslinking agent used was ethylene glycol dimethacrylate (EGDMA). The experiments were carried out on heating after the samples have been subjected to distinct thermal histories, namely isothermal stages at different temperatures below the glass transition temperature for distinct times and cooling at different rates. These studies revealed a broadening of the glass transition with increasing crosslinking degree due to the constraints imposed by the crosslinks and suggested the presence of crosslink heterogeneity in the networks. A phenomenological model based on the configurational entropy concept was used to simulate the structural relaxation phenomenon and to evaluate the temperature dependence and distribution of the relaxation times of the conformational rearrangements for these networks. The agreement between the experimental results and the simulated thermograms was quite satisfactory.

In addition, the kinetic fragility of the networks was evaluated from the results corresponding to the thermal treatments at distinct cooling rates. It was found an increase of the fragility index $m$ with increasing crosslinking degree.
\end{abstract}

(C) 2004 Published by Elsevier Ltd.

Keywords: Poly(methyl methacrylate)/ethylene glycol dimethacrylate networks; Structural relaxation; Glass transition

\section{Introduction}

It is well known that below the glass transition temperature $\left(T_{\mathrm{g}}\right)$, glass-forming systems undergo a slow relaxation phenomenon, towards the equilibrium state. This physical ageing or structural relaxation process is responsible for changes in several relevant variables in the material, such as enthalpy, volume or mechanical properties [1-3]. DSC is one of the most frequently used experimental techniques for the study of structural relaxation (see, for example, Refs. [1-3] and references cited therein), where the property chosen to investigate the process is the enthalpy. The usual procedure is to perform a scan at constant heating rate from a temperature $T_{1}$ to a temperature

\footnotetext{
* Corresponding author. Address: Polymer Engineering Department, University of Minho, Campus of Azurém, 4800-058 Guimarães, Portugal. Tel.: +351 253510 330; fax: +351 253510339 .

E-mail address: jmano@dep.uminho.pt (J.F. Mano).
}

$T_{2}$ above $T_{\mathrm{g}}$, with a previously aged sample at a temperature $T_{\mathrm{a}}$. Then a second scan from an unaged state obtained immediately after the cooling stage is a reference for evaluating the effects of ageing at $T_{\mathrm{a}}$. The aged material usually presents a more or less pronounced endothermic peak in the glass transition region.

It has been shown that the main features of the structural relaxation process can be modelled on the basis of a distribution of relaxation times that depends both on the temperature and on the structure of the material represented by the value of the relaxing variable [1,2,4-11]. The comparison between model simulation and experimental results allows to accede to a series of parameters related to the molecular mobility, and it is also possible to obtain the relaxation times of the conformational rearrangements.

The evolution of the enthalpy in response to a thermal history consisting of a series of temperature jumps from $T_{i-1}$ to $T_{\mathrm{i}}$ at time instants $t_{i}$, followed by isothermal stages is given by: 


$$
\begin{aligned}
H(t)= & H^{\mathrm{eq}}(T(t)) \\
& \left.-\sum_{i=1}^{n}\left(\int_{T_{i-1}}^{T_{i}} \Delta C_{p}(T) \mathrm{d} T\right) \phi\left(\xi-\xi_{i-1}\right)\right)
\end{aligned}
$$

where $\Delta C_{p}(T)=C_{p 1}(T)-C_{p \mathrm{~g}}(T)$ is the configurational heat capacity, the difference between the heat capacity in the equilibrium liquid state and that of the glassy state and $\xi$ is the reduced time:

$\xi=\int_{0}^{t} \frac{\mathrm{d} t^{\prime}}{\tau\left(t^{\prime}\right)}$

The relaxation function $\phi$ is assumed of the KohlrauschWilliams-Watts type [12] in the most applied models:

$$
\phi(\xi)=\exp \left(-\xi^{\beta}\right)
$$

So, in all the phenomenological models the two main properties of physical ageing, non-linearity and nonexponentiality are incorporated, but the way in which these aspects are introduced differs between models. Some reviews of the principal phenomenological models of structural relaxation, such as the one proposed by Narayanaswamy [4] and then by Moynihan et al. [5] (the NM model), the Scherer-Hodge (SH) model [7,8] or the Kovacs-Aklonis-Hutchinson-Ramos (KAHR) model [13] are available in literature $[1,2,14]$ and also recent discussions involving this type of models can be found (see for example [15-17]). Several works have shown that the NM or SH models fail to reproduce the DSC thermograms measured after different thermal histories using a single set of model parameters [18-21]. The need of history dependent model parameters contradict the theory assumptions according to which the parameters included in the model equations must be only dependent on the material [18-21].

A model was proposed by Gómez Ribelles and Monleón Pradas [10,11], the SC model, which introduced a new hypothesis related to the state attained at infinite time in the structural relaxation process at a temperature $T_{\mathrm{a}}$. One of the main assumptions of the most well known models is that an amorphous material kept in isothermal conditions in any out-of-equilibrium state would reach at infinite time the equilibrium state. It has been proposed by the SC model that the limit at infinite time of the structural relaxation process could be a metastable state with higher configurational entropy and enthalpy than the equilibrium state obtained by extrapolation. This situation would come from the collapse of the configurational rearrangements when the number of configurations available for the polymer segments attains a certain limit. To introduce this hypothesis, instead of choosing the fictive temperature to characterise the structure of the glass [22], as usual in this kind of models, the model equations were expressed in terms of the configurational entropy $S_{\mathrm{c}}[10,11,23-29]$ :
$S_{\mathrm{c}}(t)=S_{\mathrm{c}}^{\lim }(T(t))-\sum_{i=1}^{n}\left(\int_{T_{i-1}}^{T_{i}} \frac{\Delta C_{p}^{\lim }(T)}{T} \mathrm{~d} T\right) \phi\left(\xi-\xi_{i-1}\right)$

where $S_{\mathrm{c}}^{\lim }(T)$ is the configurational entropy in the metastable limit state. In order to describe this function it is necessary to introduce new model parameters, something that in principle is not desirable. To reduce the number of new parameters to a minimum $S_{\mathrm{c}}^{\lim }(T)$ was defined as shown in Fig. 1a (dotted line). The change of slope approaching the equilibrium values is gradual, covering a temperature interval of $15 \mathrm{~K}$. The change of slope shown in the sketch of Fig. 1a and determined by the reference temperature $T_{\text {ref }}$, should be to a certain extent coincident with the glass transition temperature interval. In the calculations we will take a value for $T_{\text {ref }}$ equal to the glass transition temperature determined from the intersection of the enthalpy lines corresponding to the liquid and glassy states. By this way a single additional parameter $\delta=\Delta C_{p}(T)-\Delta C_{p}^{\lim }(T)$, represented in Fig. 1, is introduced into the model.

In Eq. (4) the reduced time is given by Eq. (2), the relaxation function is the KWW equation (Eq. (3)) and the relaxation time is given by the Adam-Gibbs expression [30],

$\tau\left(T, S_{\mathrm{c}}\right)=A \exp \left(\frac{B}{T S_{\mathrm{c}}(\xi, T)}\right)$

which needs no further manipulation to be introduced in Eq. (4).

$\Delta C_{p}^{\lim }(T)$, is defined through:

$S_{\mathrm{c}}^{\lim }\left(T_{i}\right)-S_{\mathrm{c}}^{\lim }\left(T_{i-1}\right)=\int_{T_{i-1}}^{T_{i}} \frac{\Delta C_{p}^{\lim }(T)}{T} \mathrm{~d} T$

At temperatures above the glass transition region $\Delta C_{p}^{\lim }(T)$ $=\Delta C_{p}(T)$ and $S_{\mathrm{c}}^{\lim }(T)=S_{\mathrm{c}}^{\mathrm{eq}}(T)$; thus, if $T^{*}$ is a temperature above the glass transition region for any temperature $T$ in the glass transition temperature interval or below:

$S_{\mathrm{c}}^{\lim }(T)=S_{\mathrm{c}}^{\mathrm{eq}}\left(T^{*}\right)+\int_{T^{*}}^{T} \frac{\Delta C_{p}^{\lim }(T)}{T} \mathrm{~d} T$

and

$S_{\mathrm{c}}^{\mathrm{eq}}(T)=\int_{T_{2}}^{T} \frac{\Delta C_{p}(T)}{T} \mathrm{~d} T$

where $T_{2}$ is the Gibbs-DiMarzio transition temperature [31].

When all the mentioned assumptions are introduced in Eq. (4), a constitutive equation for configurational entropy out of equilibrium results which has, besides the function $\Delta C_{p}(T)$, five parameters: the parameter $\delta$ already defined, the pre-exponential constant $A$ and the parameter $B$ of the Adam-Gibbs Equation, the Gibbs-DiMarzio temperature $T_{2}$ and the exponent $\beta$ of the KWW equation.

It has been shown in many polymer systems such as 


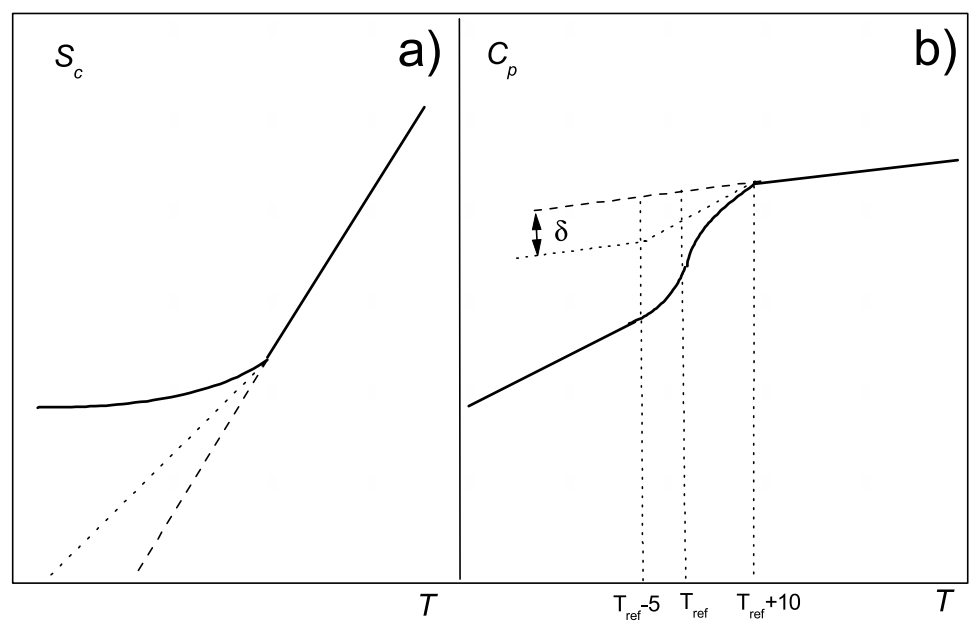

Fig. 1. (a) Sketch of the configurational entropy corresponding to the liquid state (dashed line), to an experimental cooling scan at a finite cooling rate (solid line) and to the hypothetical line of the limit states of the structural relaxation process (dotted line). (b) $C_{p}(T)$ lines corresponding to the three cases described in (a): the dashed line corresponds to the liquid state $C_{p 1}(T)$, the solid line corresponds to an experimental cooling scan and the dotted line corresponds to the specific heat capacity in the limit states of the structural relaxation process: $C_{p}^{\text {lim }}(T)$.

chain polymers, polymer networks, liquid crystal polymers, and miscible polymer blends that the model equations are able to fit with a single set of model parameters (thus material parameters) a broad set of thermograms measured after quite different thermal histories (e.g. [10,11,23-29]). To do that, the values of $S_{\mathrm{c}}^{\lim }(T)$ must be significantly higher than those of $S_{\mathrm{c}}^{\mathrm{eq}}(T)[10,11,23-29]$.

In this work the influence of the crosslinking degree on the dynamics of the glass transition of PMMA networks is analysed by DSC and the experimental results are modelled with the SC model. Several recent works have studied the influence of crosslinking degree on the thermal properties, phase separation (as revealed by DSC) and also on the morphology of blends and IPNs [32-36]. In fact, DSC has proved to be a very useful technique to characterize the heterogeneity and the increase of the temperature interval where the glass transition takes place for multi-component polymeric systems (see, for example, [37,38] and references cited therein). Moreover, it has been found that the kinetics of the structural relaxation process, closely related to the glass transition, is significantly different in multi-component systems, when compared to the process of the pure components $[28,39,40]$. The influence of the crosslink density on the kinetics of structural relaxation will also be investigated for the PMMA networks.

\section{Experimental section}

\subsection{Synthesis}

Crosslinked poly(methyl methacrylates), PMMA, were synthesised by free radical addition polymerisation of methyl methacrylate (Aldrich, 99\% pure) using as photoinitiator $0.13 \%$ by weight of benzoin (Scharlau, $98 \%$ pure). The samples were synthesised between two glass plates to form sheets of approximately $0.5 \mathrm{~mm}$ thick. Samples with distinct crosslinking degrees were prepared by adding, respectively, $0.5,1,5$ and $9 \%$, by weight of ethylene glycol dimethacrylate, EGDMA (Aldrich, 98\% pure). The monomer, crosslinking agent and initiator were used as received without further purification. Polymerisation took place at room temperature for $24 \mathrm{~h}$ under UV radiation. The low molecular weight substances remaining in the samples after polymerisation were extracted with boiling ethanol for $24 \mathrm{~h}$ and then dried in vacuo at $70{ }^{\circ} \mathrm{C}$ for several weeks until the weight remained constant. Finally the samples were dried in vacuo at $180{ }^{\circ} \mathrm{C}$ for $1 \mathrm{~h}$ in order to eliminate possible residues that still remain in the sample. The samples are referred in the text as PMMA0.5, PMMA1, ..., where the number after the sample refers to the amount of crosslinking agent.

\subsection{DSC experiments}

The DSC experiments were performed with a DSC7 Perkin Elmer differential scanning calorimeter. The usual calibration procedure of differential scanning calorimeters, based on the melting points of high purity standards was followed prior to the experiments. The temperature of the equipment was calibrated with indium and lead standards and only the same indium sample was used for the heat flow calibration. The calibrations were always performed at the same heating rate of the runs. In addition, the ageing temperature values in the DSC ageing experiments were corrected by performing calibrations at distinct heating rates and using the extrapolated value at zero heating rate for the temperature calibration. The cooling system used was a water bath. Nitrogen was used as a purge gas to improve the temperature control. The baseline correction was also used for all the experiments described in this work. This means that a scan was previously carried out with both furnaces 
empty and at the same experimental conditions (temperature range and heating rate) of a given experiment and the final result is the subtraction between these two scans.

For each crosslinking degree a single sample, sealed in an aluminium pan (capacity $=50 \mu \mathrm{l}$ ), was used in all DSC experiments. The sample weights were 10.291, 10.390, 10.295 and $10.544 \mathrm{mg}$ for PMMA0.5, PMMA1, PMMA5 and PMMA9, respectively.

Thermal histories included coolings at different rates $\left(0.5,1,2,5,10,20\right.$ and $\left.40{ }^{\circ} \mathrm{C} / \mathrm{min}\right)$ for PMMA 0.5 , PMMA5 and PMMA9 as well as isothermal annealing stages at several temperatures $\left(T_{\mathrm{g}}, T_{\mathrm{g}}-5^{\circ} \mathrm{C}, T_{\mathrm{g}}-10{ }^{\circ} \mathrm{C}, T_{\mathrm{g}}-20^{\circ} \mathrm{C}\right.$ and $\left.T_{\mathrm{g}}-35^{\circ} \mathrm{C}\right)$ over different time intervals $t_{\mathrm{a}}(120,1260$ and $4020 \mathrm{~min}$ ), for all the samples. For $t_{\mathrm{a}}=1260 \mathrm{~min}$ some additional experiments were performed for each network in order to better evaluate the enthalpy loss between the aged and unaged states. The measuring scan was carried out during subsequent heating at constant rate, $10{ }^{\circ} \mathrm{C} / \mathrm{min}$, from 50 to $180^{\circ} \mathrm{C}$. Several reference experiments, where the measuring scan is carried out after a cooling at $40{ }^{\circ} \mathrm{C} / \mathrm{min}$ (i.e. $t_{\mathrm{a}}=0 \mathrm{~min}$ ), were performed for each sample. The $T_{\mathrm{g}}$ values (calculated from the midpoint of the specific heat capacity increment at the glass transition $\Delta C_{p}\left(T_{\mathrm{g}}\right)$ were obtained from several reference scans (i.e., on heating) performed for all the samples and are presented in Table 1 , as well as the $\Delta C_{p}\left(T_{\mathrm{g}}\right)$ values.

\section{Results and discussion}

\subsection{Cooling at distinct rates}

By looking at Table 1 it can be observed how the increase in the amount of EGDMA from 0.5 to $9 \mathrm{wt} \%$ leads to an important increase in $\sim 12{ }^{\circ} \mathrm{C}$ in the $T_{\mathrm{g}}$ value and to a decrease in $\Delta C_{p}\left(T_{\mathrm{g}}\right)$ related to the decrease in mobility imposed by the crosslinks. The decrease in $\Delta C_{p}\left(T_{\mathrm{g}}\right)$ with crosslink density has been found previously for distinct networks [35,36,41,42].

Fig. 2 shows the heating scans for PMMA0.5 in terms of the normalised heat flow, $(\mathrm{d} Q / \mathrm{d} t)_{\text {norm }}=\dot{Q}_{\text {norm }}$, i.e. the difference between the heat fluxes supplied to the sample furnace and the reference furnace divided by the sample weight and the rate of the experiment. These experiments were performed after cooling at the rates $q_{\mathrm{c}}$ indicated in the graph. The effects of physical ageing resulting from these thermal treatments are almost undetectable, i.e. the expected increase in the peak height as $q_{\mathrm{c}}$ decreases is not visible in Fig. 2. It was only detected a small and extremely broad exothermic peak at the lowest cooling rates $\left(1\right.$ and $0.5^{\circ} \mathrm{C} /$ min). For the other two samples (PMMA5 and PMMA9) it was found that the effects of the thermal treatments (not shown) are less pronounced than for PMMA0.5. A comparison between the reference scans of the distinct samples revealed the broadening of the glass transition as the crosslink density increases. A similar shift and broadening of the glass transition with increasing crosslinking degree was already observed by DSC for PMMA crosslinked with the same agent [36].

From the results shown in Fig. 2 it is possible to calculate the limiting fictive temperature [22] attained in the glassy state after the cooling down process, $T_{\mathrm{f}}^{\prime}$, using either Eq. (9) or (10) for the lowest temperature attained in the cooling process [5]:

$$
\begin{gathered}
H(T)=H^{\mathrm{eq}}\left(T_{\mathrm{f}}\right)-\int_{T}^{T_{\mathrm{f}}} C_{p \mathrm{~g}}\left(T^{\prime}\right) \mathrm{d} T^{\prime} \\
\int_{T_{\mathrm{f}}}^{T^{*}}\left(C_{p l}\left(T^{\prime}\right)-C_{p \mathrm{~g}}\left(T^{\prime}\right)\right) \mathrm{d} T^{\prime} \\
=\int_{T}^{T^{*}}\left(C_{p}\left(T^{\prime}\right)-C_{p \mathrm{~g}}\left(T^{\prime}\right)\right) \mathrm{d} T^{\prime}
\end{gathered}
$$

This temperature corresponds to the glass transition temperature determined by the intersection point of the enthalpy lines in the equilibrium liquid and the glassy states [5]. Fig. 2 also shows the $\ln q_{\mathrm{c}}$ vs. $1 / T_{\mathrm{f}}^{\prime}$ plot for PMMA0.5 (inset graphics).

Moreover, it was found $[43,44]$ that the calculation of the $T^{\prime}{ }_{\mathrm{f}}$ values after cooling the material at different rates $q_{\mathrm{c}}$ from the liquid state permits to obtain the apparent activation energy around $T_{\mathrm{g}}$ from DSC measurements, usually called $\Delta h^{*}$ :

$$
\frac{\mathrm{d} \ln \tau^{\mathrm{eq}}}{\mathrm{d}(1 / T)}=-\frac{\mathrm{d} \ln q_{\mathrm{c}}}{\mathrm{d}\left(1 / T_{\mathrm{f}}^{\prime}\right)}=\frac{\Delta h^{*}}{R}
$$

The $\Delta h^{*}$ values found for PMMA0.5, PMMA5 and PMMA9 by applying Eq. (11) were 533, 772 and $846 \mathrm{~kJ} /$ mol, respectively. So, as the crosslink density is getting higher the apparent activation energy associated to the glass transition increases.

DSC can be used to evaluate the fragility of a system. The fragility is related to the magnitude of the decrease in

\begin{tabular}{|c|c|c|c|c|}
\hline & PMMA0.5 & PMMA1 & PMMA5 & PMMA9 \\
\hline$T_{\mathrm{g}}\left({ }^{\circ} \mathrm{C}\right)$ & $118.0 \pm 0.5$ & $118.5 \pm 0.5$ & $121.4 \pm 0.5$ & $130.0 \pm 0.5$ \\
\hline$\Delta C_{p}\left(T_{\mathrm{g}}\right)(\mathrm{J} / \mathrm{g} \mathrm{K})$ & $0.26 \pm 0.02$ & $0.24 \pm 0.02$ & $0.22 \pm 0.02$ & $0.17 \pm 0.02$ \\
\hline$m$ & 71 & & 102 & 110 \\
\hline
\end{tabular}

Table 1

Glass transition temperatures $\left(T_{\mathrm{g}}\right)$ of the PMMA networks and specific heat capacity increment at the glass transition $\left(\Delta C_{p}\left(T_{\mathrm{g}}\right)\right)$, measured from the DSC heating scans at $10{ }^{\circ} \mathrm{C} / \mathrm{min}$. The samples were previously cooled at $40^{\circ} \mathrm{C} / \mathrm{min}$. In this table are also included the fragility index $(\mathrm{m})$ calculated by applying Eq. (12) 


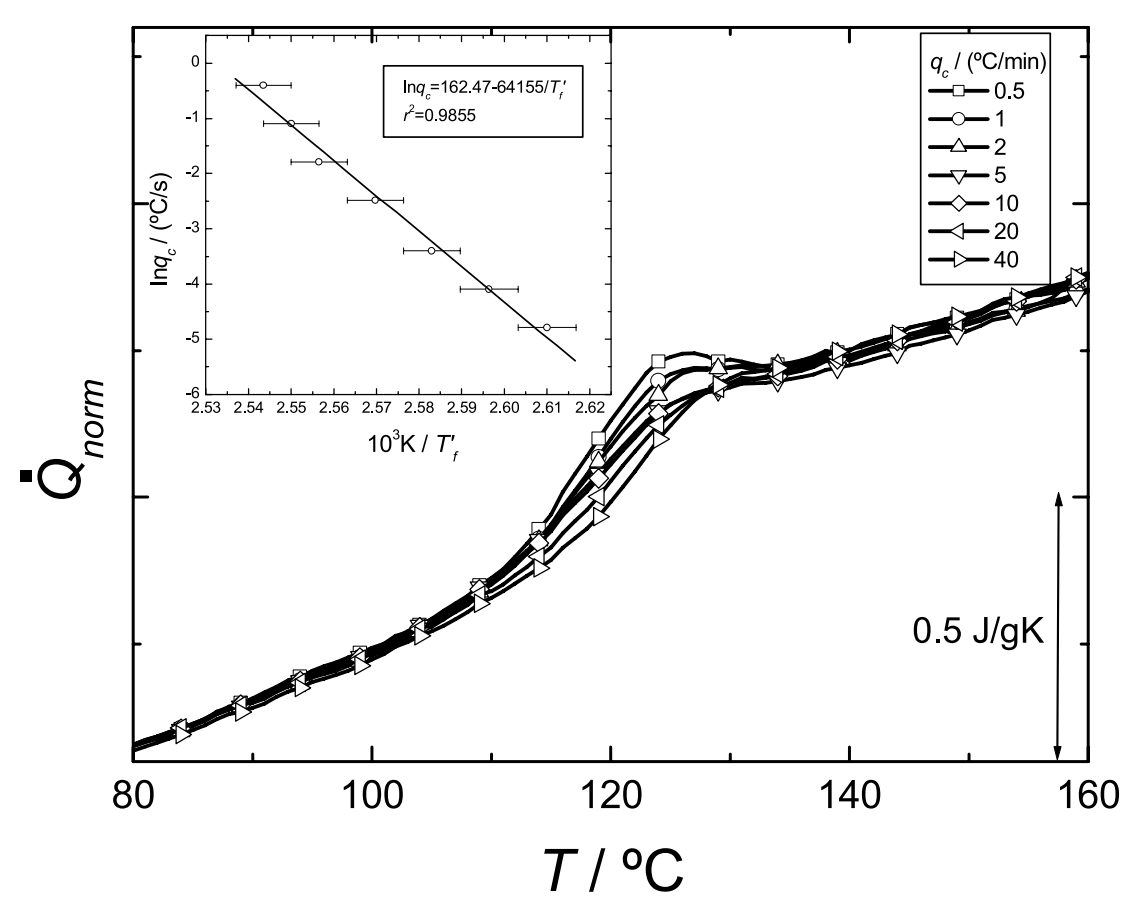

Fig. 2. Temperature dependence of the normalised heat flow measured in heating DSC scans at $10{ }^{\circ} \mathrm{C} / \mathrm{min}$ of PMMA0.5, previously cooled at the rates indicated in the graphics. Inset graphics: fictive temperature in the glassy state, after cooling at different rates $q_{\mathrm{c}}$ from the liquid state.

$\log \tau$ with decreasing $T_{\mathrm{g}} / T$ [45-47] and may be parameterised by the steepness 'index' $m$ :

$m=\Delta h^{*} /\left[\ln (10) R T_{\mathrm{g}}\right]$

The $m$ values obtained for PMMA0.5, PMMA5 and PMMA9 are included in Table 1 . The $m$ value for PMMA0.5 is somewhat lower than the one reported in literature for uncrosslinked PMMA $(m=103)$ [48], also determined by DSC. However, the use of DSC in the determination of $m$ may lead to great errors, especially in fragile materials, where the variation of $T^{\prime}{ }_{\mathrm{f}}$ with $q_{\mathrm{c}}$ is less pronounced, introducing significant inaccuracy in $\Delta h^{*}$ determination (see Eq. (11)). This could be the reason for the difference between the values obtained in this work and the one found by Donth [48]. Nevertheless, these high values indicate that the studied PMMA networks are kinetically fragile systems. The same variation of fragility with crosslinking degree observed in Table 1 was already found in PMMA/EGDMA networks by DMA and creep [49]. As has been recently reported [50] for several polymeric systems there is a good agreement between the fragilities measured by DSC and by mechanical or dielectric spectroscopies. Nevertheless, the DSC values are usually higher than the values obtained by mechanical or dielectric spectroscopies [50], but this was not observed in the present work.

The thermodynamic fragility may be also evaluated by DSC and in this case it was used for the criterion of the step change on the specific heat capacity $\Delta C_{p}$ at $T_{\mathrm{g}}$. These values can be found in Table 1 . They are similar with the value found in literature for a PMMA: $\Delta C_{p}\left(T_{\mathrm{g}}\right)=0.25 \mathrm{~J} / \mathrm{g} \mathrm{K}$ [51], although the obtained values are somewhat smaller as expected for crosslinked materials. Comparing this value of $\Delta C_{p}$ with values found for other systems [51,52], the PMMA networks can be classified as thermodynamically strong systems. This classification is in agreement with the one found in Ref. [53] for PMMA, although the authors used the $\left(C_{p \mathrm{l}} / C_{p \mathrm{~g}}\right)$ criterion.

\subsection{Isothermal annealings}

The PMMA networks were subjected to different thermal treatments, already described in Section 2. The heating scans obtained after these thermal histories are shown in Figs. 3-6. A reference scan $\left(t_{\mathrm{a}}=0 \mathrm{~s}\right)$ for each network is also presented in these figures, for the sake of comparison.

The broadening of the glass transition as the crosslink density increases, already mentioned in Section 3.1, can be also observed in these results. The broadening of the glass transition can be due to several factors: a broad distribution of relaxation times, a low apparent activation energy around the glass transition temperature, or the composition heterogeneity of the material as can be the case of polymer blends in which different domains in the material have different composition and thus, different $T_{\mathrm{g}}$. The latter was also observed in PMMA/PMA IPN's highly crosslinked with $10 \%$ by weight of EGDMA in which a single but extremely broad glass transition, covering a temperature range of $\sim 100{ }^{\circ} \mathrm{C}$ was observed [36]. It was also found that the broadening of the glass transition is not symmetric around the glass transition corresponding to the average composition due to the temperature dependence of the length of cooperativity [36]. It is expected that the 

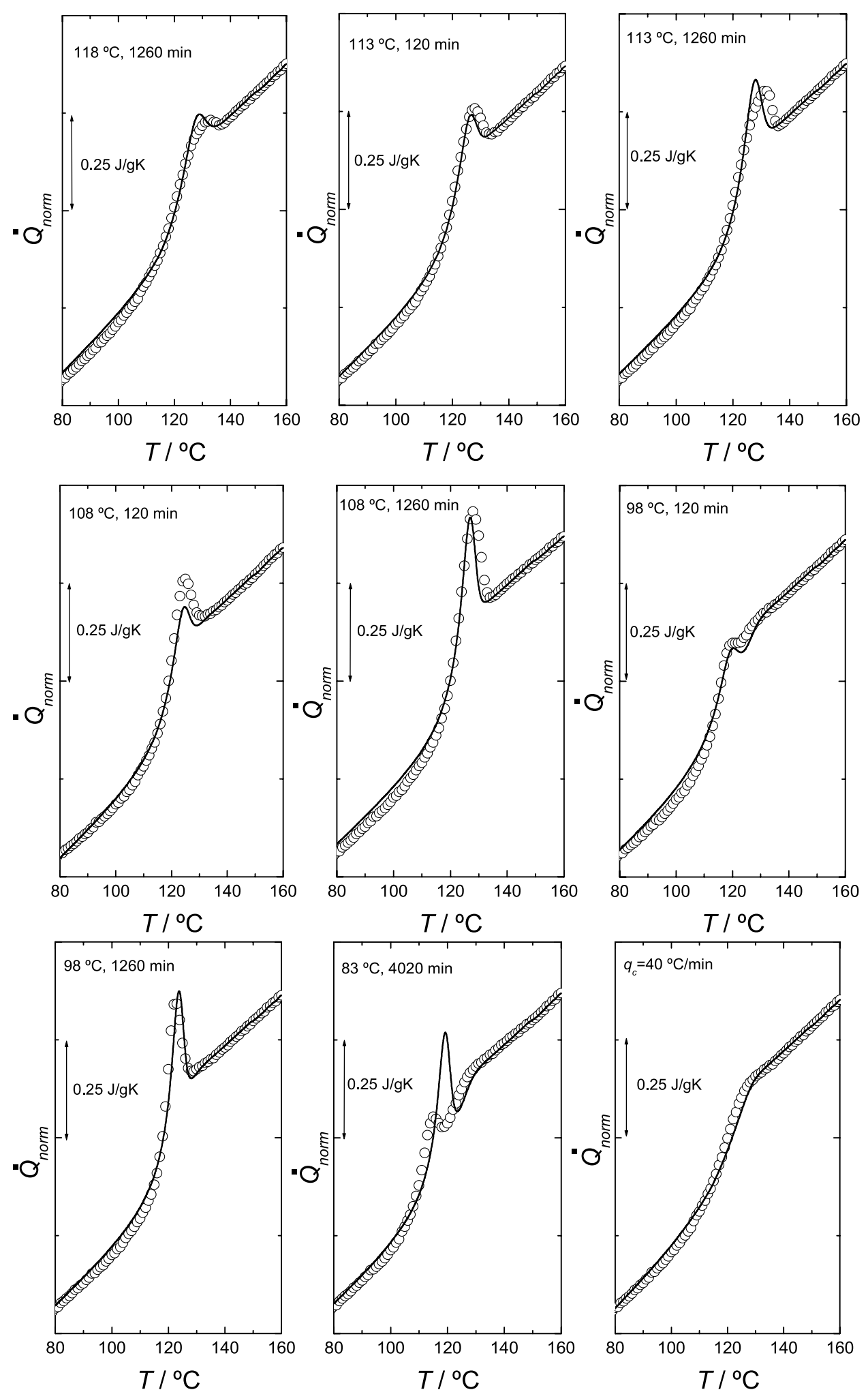

Fig. 3. (O) Temperature dependence of the normalised heat flow of PMMA0.5 measured in heating DSC scans at $10^{\circ} \mathrm{C} / \mathrm{min}$, previously subjected to distinct thermal treatments (in the graphics). (-) SC model curves for the same sample. The simulated curves were calculated under the assumption $S_{\mathrm{c}}^{\lim }(T)>S_{\mathrm{c}}^{\mathrm{eq}}(T)$ and the corresponding parameters of Table 2 . 

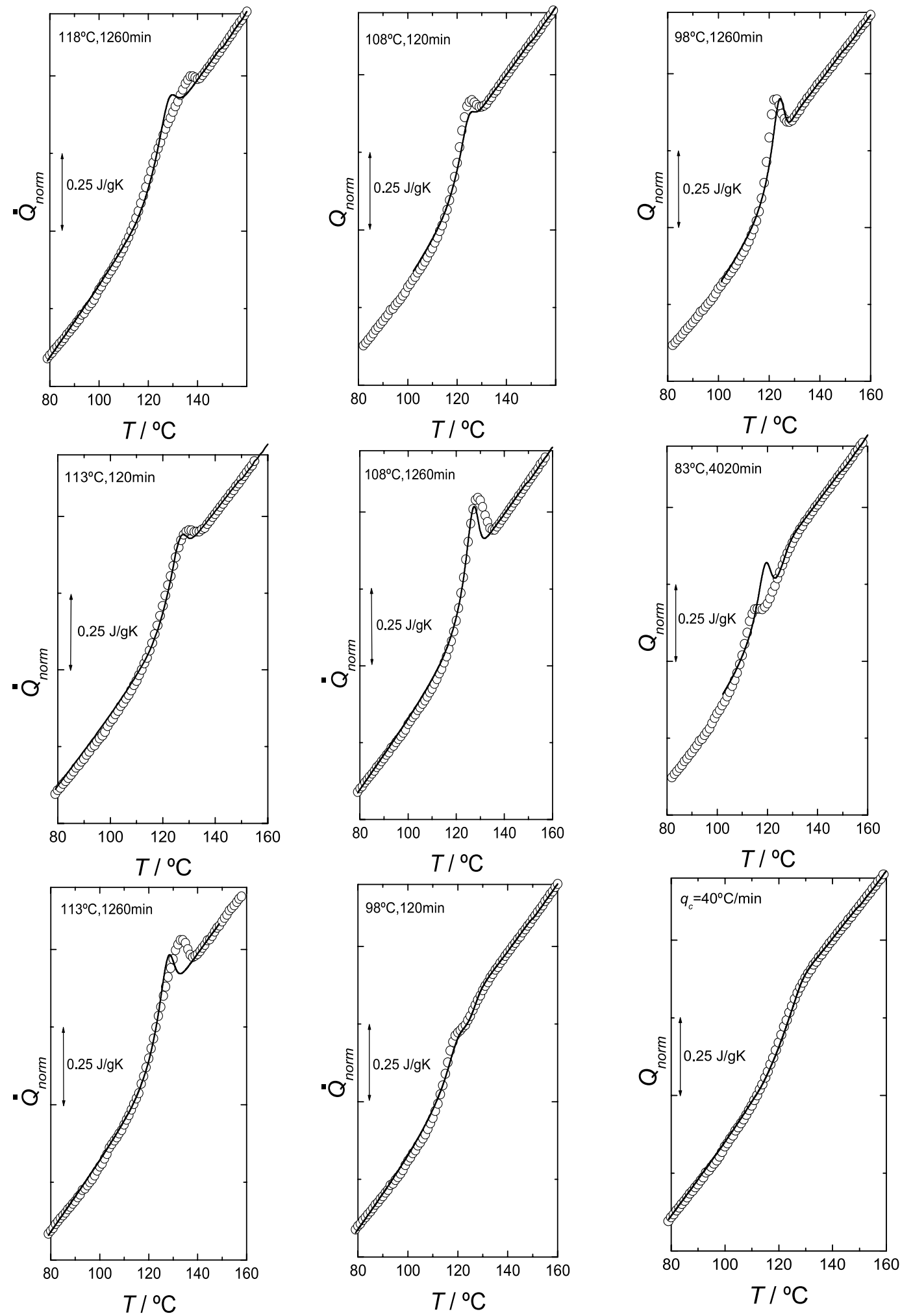

Fig. 4. (O) Temperature dependence of the normalised heat flow of PMMA1 measured in heating DSC scans at $10{ }^{\circ} \mathrm{C} / \mathrm{min}$, previously subjected to distinct thermal treatments (in the graphics). (-) SC model curves for the same sample. The simulated curves were calculated under the assumption $S_{\mathrm{c}}^{\mathrm{lim}}(T)>S_{\mathrm{c}}^{\mathrm{eq}}(T)$ and the corresponding parameters of Table 2 . 
modelling of the DSC results of the PMMA networks can provide more insights about their behaviour.

The effect of the crosslinks on the glass transition dynamics of epoxy resins has also been studied by DSC, and structural relaxation studies were performed [54]. In this particular work the effect of the crosslink length (i.e. the length of the crosslinking agent) on the enthalpy relaxation of these systems was analysed. It was found that the decrease in the crosslink length results in an increase in $T_{\mathrm{g}}$, and a decrease in both $\Delta C_{p}$ and the $\beta_{\mathrm{Kww}}$ parameter. The relaxation process also becomes more cooperative as the crosslink length decreases.

Typically, when the ageing temperature $T_{\mathrm{a}}$ is close to $T_{\mathrm{g}}$, the ageing peak overlaps the glass transition. When $T_{\mathrm{a}}$ is far below $T_{\mathrm{g}}$, i.e. below the range in which the glass transition occurs, the ageing peak may also appear at temperatures below $T_{\mathrm{g}}$, and has been called as sub- $T_{\mathrm{g}}$ peak or pre-peak $[55,56]$. The shape and the temperature of the ageing peak strongly depend on both $T_{\mathrm{a}}$ and the ageing time $t_{\mathrm{a}}$. In Figs. $3-6$, an ageing peak superposed to the glass transition is observed for all the samples at $T_{\mathrm{a}}=T_{\mathrm{g}}, T_{\mathrm{a}}=T_{\mathrm{g}}-5{ }^{\circ} \mathrm{C}$ and even at $T_{\mathrm{a}}=T_{\mathrm{g}}-10{ }^{\circ} \mathrm{C}$. Sub- $T_{\mathrm{g}}$ peaks were detected at $T_{\mathrm{a}}=$ $T_{\mathrm{g}}-20^{\circ} \mathrm{C}$ and more clearly at $T_{\mathrm{a}}=T_{\mathrm{g}}-35^{\circ} \mathrm{C}$. These peaks are at a lower temperature the lower $T_{\mathrm{a}}$ is. For a given $T_{\mathrm{a}}$, the effect of $t_{\mathrm{a}}$ is the usually observed in this kind of experiments, i.e. the shift of the ageing peak towards higher temperatures and the increase of the peak height as $t_{\mathrm{a}}$ increases. Several structural relaxation studies of uncrosslinked PMMA, in which this type of behaviour is reported, can be found in literature (e.g. [29,57-60]).

In Figs. 3-6 it is also observed that, in general, as the crosslinking degree increases the effects of a given thermal treatment are getting less pronounced, due to the decrease of $\Delta C_{p}\left(T_{\mathrm{g}}\right)$ and to the constraints imposed by the crosslinks to segmental motion. This is more evident in Fig. 7, which represents the enthalpy loss between the aged and unaged states $\Delta H\left(t_{\mathrm{a}}\right)$ for $t_{\mathrm{a}}=1260 \mathrm{~min}$, as a function of $T_{\mathrm{a}} . \Delta H\left(t_{\mathrm{a}}\right)$ was calculated by applying the following expression:

$$
\begin{aligned}
\Delta H\left(t_{\mathrm{a}}\right) & =\int_{T_{1}}^{T_{2}}\left(C_{p \mathrm{a}}(T)-C_{p \mathrm{r}}(T)\right) \mathrm{d} T \\
& =\frac{1}{q_{\mathrm{h}} m_{\mathrm{s}}} \int_{T_{1}}^{T_{2}}\left(\frac{\mathrm{d} Q_{\mathrm{a}}(T)}{\mathrm{d} t}-\frac{\mathrm{d} Q_{\mathrm{r}}(T)}{\mathrm{d} t}\right) \mathrm{d} T
\end{aligned}
$$

where $C_{p \mathrm{a}}-C_{p \mathrm{r}}$ is the difference between the experimental heat capacities of the aged and the unaged sample. The integral is evaluated between $T_{1}$, a temperature low enough in the glassy state and a convenient temperature limit $T_{2}$ above $T_{\mathrm{g}}$ (in the equilibrium phase). $C_{p \mathrm{a}}-C_{p \mathrm{r}}$ can be obtained from the heat flux measured in the aged sample $\left(\mathrm{d} Q_{a} / \mathrm{d} t\right)$ and the heat flux of the reference sample (unaged, i.e. $\left.t_{\mathrm{a}}=0\right)\left(\mathrm{d} Q_{\mathrm{r}} / \mathrm{d} t\right)$, correcting for the heating rate, $q_{\mathrm{h}}$, and the mass, $m_{\mathrm{s}}$, as it is shown in Eq. (13).

This kind of plot, presented in Fig. 7, provides a better picture of the structural relaxation kinetics of the PMMA networks. The presence of an ageing peak after annealing at a given $T_{\mathrm{a}}$ reveals that some conformational motions are still possible and this conducts to an approach of the enthalpy, during the isothermal period, towards its equilibrium value.

It can be seen for all the samples, starting from the lowest $T_{\mathrm{a}}$, the increase of the peak height as $T_{\mathrm{a}}$ increases, because the approach to equilibrium is faster the higher the temperature is. On the other hand, for a sufficiently high $T_{\mathrm{a}}$, close to the $T_{\mathrm{g}}$ value, the rate of the structural relaxation process is high, but the variation of enthalpy produced is small because the material is close to equilibrium during the whole process. A further increase of $T_{\mathrm{a}}$ would lead to a value at which there is no difference between the scan measured on the aged sample and the reference scan. This would indicate that at the beginning of the isothermal period the sample was already in equilibrium.

From the previous considerations it can be said that this kind of plots defines a temperature interval in which the conformational rearrangements take place in the glassy state at a significant rate. A recent work [40] shows how the $H\left(t_{\mathrm{a}}\right)$ vs. $T_{\mathrm{a}}$ representations can be helpful for investigating the conformational mobility, in this case of poly(methyl acrylate-poly(methyl methacrylate) IPN's. In Fig. 7 it is clearly observed a shift of the $\Delta H\left(t_{\mathrm{a}}\right)$ vs. $T_{\mathrm{a}}$ curves to higher temperatures and also a broadening of the curves as the crosslinking degree increases, i.e. an increase of the temperature range in which the structural relaxation effects are measurable. These observations are obviously related to the increase in the $T_{\mathrm{g}}$ value and in the breadth of the glass transition with increasing crosslinking degree, detected in the reference scans. In this figure there are not enough points to define the temperature intervals where the conformational rearrangements in the glassy state occur at significant rate for each network, but it can be said that this interval seems to increase as the crosslinking degree increases. For PMMA0.5 and PMMA1 the temperature of the maximum $\Delta H\left(t_{\mathrm{a}}\right)$ is similar, as expected, because both samples have almost the same $T_{\mathrm{g}}$. In these curves the extrapolated value of temperature for $\Delta H\left(t_{\mathrm{a}}\right) \rightarrow 0$, i.e. when the ageing effects are not visible at high temperatures, would approximately give the 'end' value of $T_{\mathrm{g}}$. As the curves are not well defined, these values were not calculated.

As referred in [40], the $\Delta H\left(t_{\mathrm{a}}\right)$ vs. $T_{\mathrm{a}}$ plot depends on the chosen $t_{\mathrm{a}}$, because the measured values of $\Delta H\left(t_{\mathrm{a}}\right)$ increase with increasing $t_{\mathrm{a}}$. In principle, these variations would be small when $T_{\mathrm{a}}$ is close to $T_{\mathrm{g}}$ and the sample reaches a state very close to the equilibrium during the ageing stage. This would result in a value of $\Delta H\left(t_{\mathrm{a}}\right)$ independent of $t_{\mathrm{a}}$ for this temperature range. At lower $T_{\mathrm{a}}$, in the temperature range of the maximum $\Delta H\left(t_{\mathrm{a}}\right)$ in Fig. 7, it is expected a linear dependence of $\Delta H\left(t_{\mathrm{a}}\right)$ with the logarithm of time in a large time range [61,62]. Usually, the slope $\Delta H\left(t_{\mathrm{a}}\right)$ vs. $\log t_{\mathrm{a}}$ does not depend on the temperature in this range and changing $t_{\mathrm{a}}$ does not alter significantly the temperature of the maximum in Fig. 7. Off course that the temperature range in which the physical ageing effects are visible extends in the low 

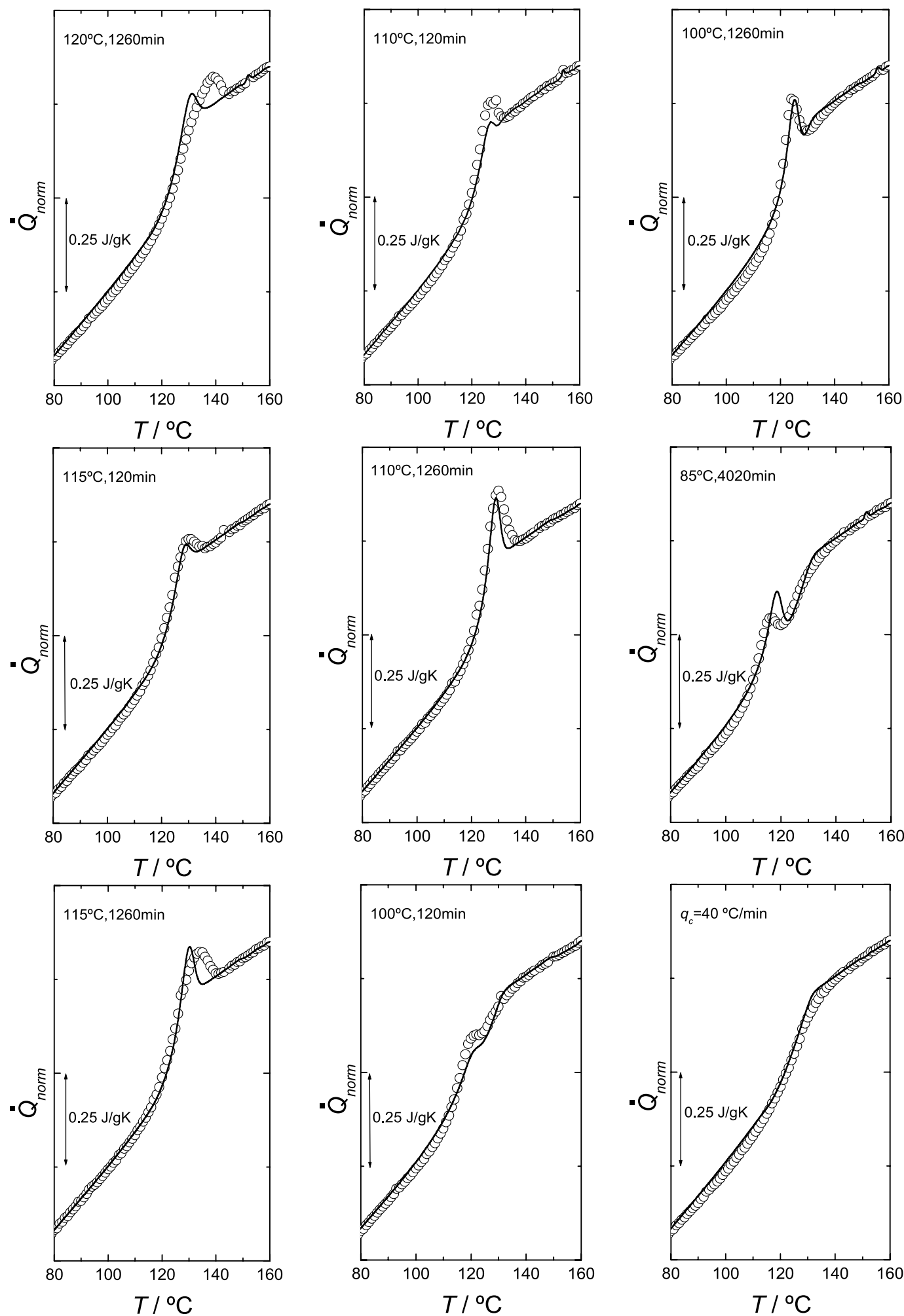

Fig. 5. ( $\bigcirc)$ Temperature dependence of the normalised heat flow of PMMA5 measured in heating DSC scans at $10{ }^{\circ} \mathrm{C} / \mathrm{min}$, previously subjected to distinct thermal treatments (in the graphics). (-) SC model curves for the same sample. The simulated curves were calculated under the assumption $S_{\mathrm{c}}^{\text {lim }}(T)>S_{\mathrm{c}}^{\text {eq }}(T)$ and the corresponding parameters of Table 2 . 

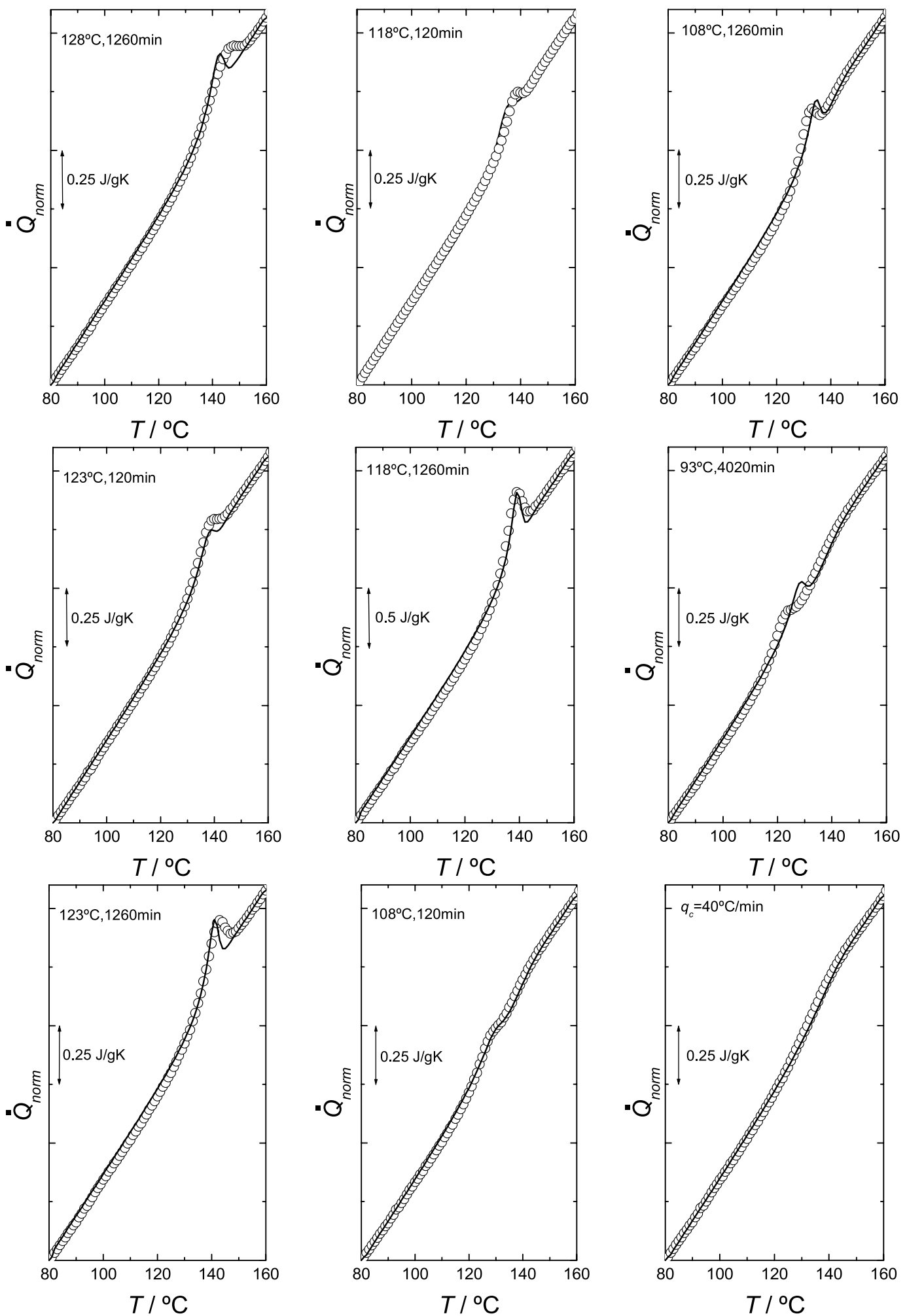

Fig. 6. (O) Temperature dependence of the normalised heat flow of PMMA9 measured in heating DSC scans at $10{ }^{\circ} \mathrm{C} / \mathrm{min}$, previously subjected to distinct thermal treatments (in the graphics). (-) SC model curves for the same sample. The simulated curves were calculated under the assumption $S_{\mathrm{c}}^{\mathrm{lim}}(T)>S_{\mathrm{c}}^{\mathrm{eq}}(T)$ and the corresponding parameters of Table 2. 


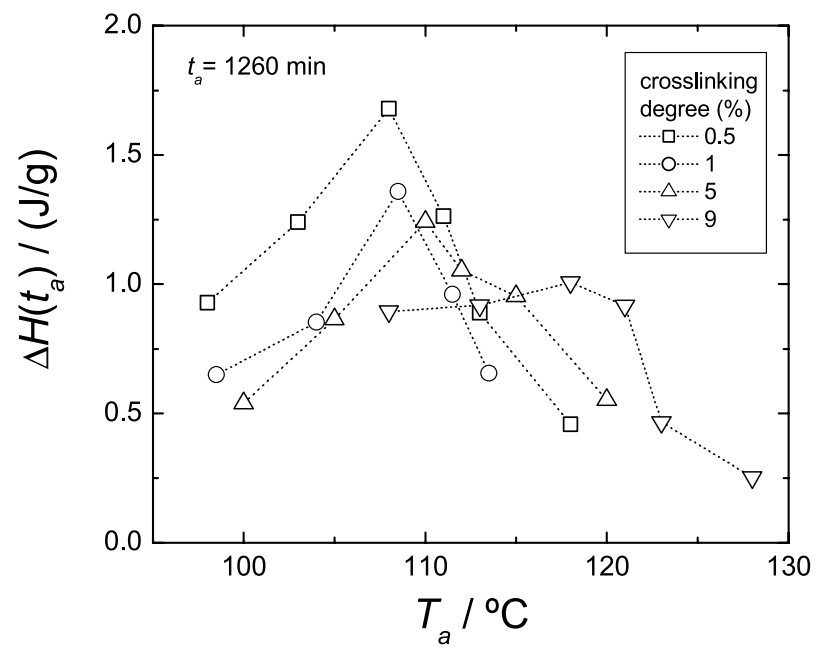

Fig. 7. Enthalpy loss between the aged and unaged states vs ageing temperature for the PMMA networks, calculated for an ageing period of $1260 \mathrm{~min}$. The lines are only guides to the eye.

temperature-side as $t_{\mathrm{a}}$ increases. However, as the curve has a sigmoidal form, only increasing $t_{\mathrm{a}}$ for several decades will conduct to great variations.

\subsection{Modelling of DSC results}

The nine heating scans, presented in Section 3.2 for each network, were fitted with the phenomenological model described in Section 1. In this case the typical linear dependence of $\Delta C_{p}$ with temperature [63] was used for the model calculations. The simulations were conducted for all the samples under the assumption $S_{\mathrm{c}}^{\mathrm{lim}}(T)>S_{\mathrm{c}}^{\mathrm{eq}}(T)$, i.e. assuming that the equilibrium state would not be reached. A value of $B=750 \mathrm{~J} / \mathrm{g}$ was kept constant for all the samples. This value was chosen from preliminary modelling results (not shown); it was the $B$ value that conducted to more realistic $A$ and $T_{\mathrm{g}}-T_{2}$ values for a typical amorphous polymer. The simulated curves under these assumptions are also shown in Figs. 3-6. The model parameters found for the PMMA networks are listed in Table 2.

In general, it can be said that the fits are quite satisfactory for all the samples. Nevertheless, for some conditions the model does not reproduce well the experimental behaviour, e.g. the predicted ageing peak has a higher intensity than the experimental one. This is seen in Figs. 3 and 4 for $T_{\mathrm{a}}=83^{\circ} \mathrm{C}$ and $t_{\mathrm{a}}=4020 \mathrm{~min}$ and in Fig. 5 for $T_{\mathrm{a}}=85^{\circ} \mathrm{C}$ and $t_{\mathrm{a}}=$ $4020 \mathrm{~min}$. This fact can be attributed to the fitting routine, in which the error function to minimise is a sum of the errors in the different curves, where those with highest peaks have stronger influence. Looking at Figs. 3-6 it can also be seen that some of the ageing peaks are broader and have a form that is not the general form observed for a single phase. This is evident for some thermal treatments, e.g. the curves shown in Fig. 4 for $T_{\mathrm{a}}=113{ }^{\circ} \mathrm{C}$ and $t_{\mathrm{a}}=1260 \mathrm{~min}$ or in Fig. 5 for $T_{\mathrm{a}}=120^{\circ} \mathrm{C}$ and $t_{\mathrm{a}}=1260 \mathrm{~min}$.
The SC model was developed with the assumption of the existence of a single-phase system. We suggest that the presence of two separate phases, perhaps one of them with higher crosslink density and hence with a higher glass transition temperature, could be the reason for not obtaining better fittings for the PMMA networks. In fact, physical ageing results of uncrosslinked PMMA were already modelled with the SC model [29] and the fittings were much better than the ones corresponding to the networks, which supports the presented argument. Also, a qualitative comparison of the ageing peaks of uncrosslinked PMMA [29] with the ones detected in this work for the networks indicates that the former are narrower than the latter.

One of the open problems in the physics and technology of cross-linked polymers is precisely the characterisation of the micro- or nano-heterogeneity introduced during the network formation: the non-uniform distribution of crosslinks, including the possibility of cross-links agglomerations, broad distribution of chain lengths between cross-links, dangling chains, cyclization, entanglements, etc (see, for instance, [64-66]). The increase in crosslink density increases the heterogeneity as well, as discussed in many studies of polymeric networks and gels (e.g. [64,65,67-70]). This supports the explanation suggested in this work.

The heterogeneous distribution of crosslinks in PMMA/EGDMA networks would mean that, during the polymerisation, slightly crosslinked PMMA regions and highly crosslinked PMMA regions were formed. It has been proposed that the crosslink heterogeneity is directly reflected in the breadth of the glass transition [71]. In this case the increase in the crosslink density results in a broader glass transition as seen in this work and also, for example, in polyurethane networks [32] or vinyl ester networks [35]. However, for some authors [35] it is not clear whether this effect is only a natural consequence of an increased crosslink density, reflecting the variations in the amount and distribution of free volume with crosslinking, or if it is due to the increased crosslink heterogeneity.

It should be pointed that the existence of heterogeneity is very difficult to detect by DSC or by other techniques, without physical ageing studies. In fact, these kinds of studies have revealed the presence of distinct phases and/or the immiscibility of multi-component systems, even when the glass transition temperatures of the phases are close to each other and a single glass transition is identified for the unaged sample $[61,72,73]$. The observation of two differentiated phases in low-crystallinity PET in a previous work [74], only detected with physical ageing studies, also strengthens the usefulness of such kind of tests.

The $\beta$ values of the networks are in agreement with the values between 0.30 and 0.33 found in literature by DSC $[29,73]$ for uncrosslinked PMMA, i.e. they present somewhat lower values as typical for crosslinked systems. It could be expected a larger variation of the $\beta$ values with increasing crosslinking degree, because the $\alpha$-relaxation is clearly broader for PMMA9 than for the other samples as 
Table 2

Model parameters of the PMMA networks determined by the least-squares routine under the assumption $S_{\mathrm{c}}^{\mathrm{lim}}(T)>S_{\mathrm{c}}^{\mathrm{eq}}(T)$

\begin{tabular}{|c|c|c|c|c|}
\hline & $\delta$ & $\beta$ & $T_{2}\left({ }^{\circ} \mathrm{C}\right)$ & $\ln (A / s)$ \\
\hline PMMA0.5 & $0.07 \pm 0.01$ & $0.28 \pm 0.004$ & $52.1 \pm 0.5$ & $-34.3 \pm 0.5$ \\
\hline PMMA1 & $0.11 \pm 0.01$ & $0.27 \pm 0.004$ & $53.2 \pm 0.5$ & $-38.1 \pm 0.5$ \\
\hline PMMA5 & $0.14 \pm 0.01$ & $0.27 \pm 0.004$ & $75.3 \pm 0.5$ & $-42.4 \pm 0.5$ \\
\hline PMMA9 & $0.02 \pm 0.01$ & $0.26 \pm 0.004$ & $54.4 \pm 0.5$ & $-44.5 \pm 0.5$ \\
\hline
\end{tabular}

$B=750 \mathrm{~J} / \mathrm{g}$ for all the networks.

shown in Figs. 3-6. However, as referred before, the breadth of a distribution is not only related with the $\beta$ value i.e. with a larger distribution of characteristic times, but also with the apparent activation energy of the relaxation (i.e. with its fragility).

A high value of $\delta$ when compared with the corresponding $\Delta C_{p}\left(T_{\mathrm{g}}\right)$, indicates that the limit state of structural relaxation is far from equilibrium. Moreover, entanglements or crosslinks can be associated to the existence of a limit metastable state for structural relaxation $[10,74,75]$. In Ref. [75] the authors refer that the classical models as the NM or $\mathrm{SH}$, models due to the definition of the equilibrated glass in
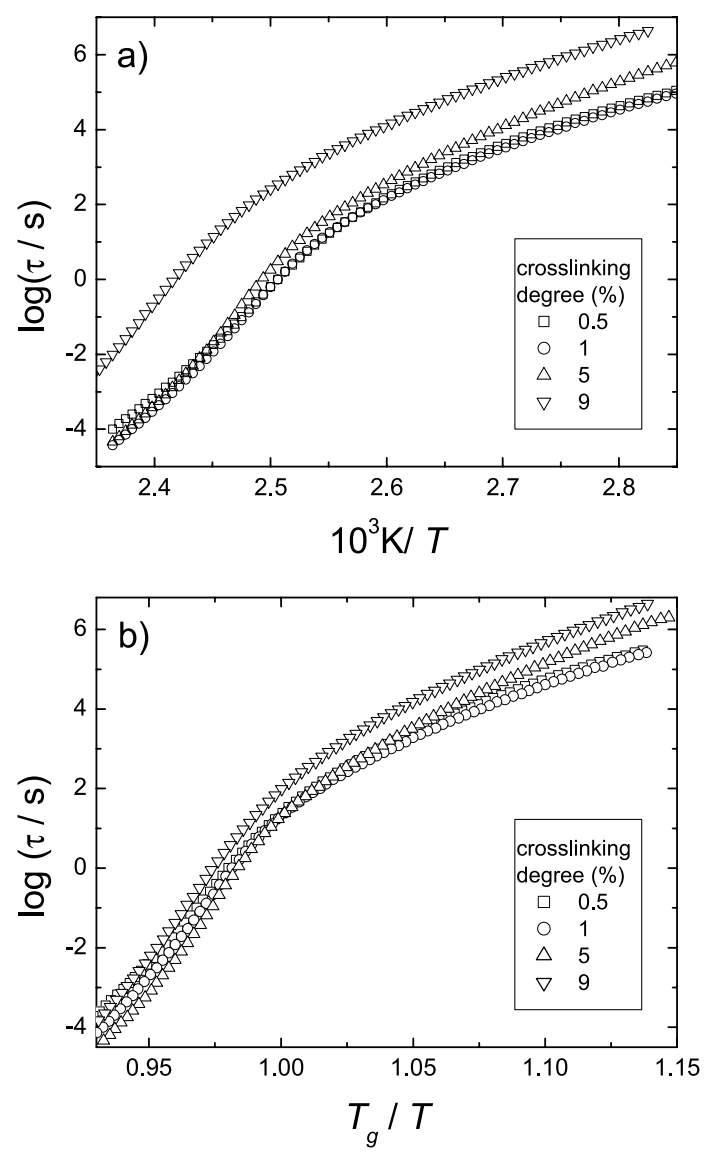

Fig. 8. (a) Temperature dependence of the relaxation times and (b) Angell plot, calculated for the PMMA networks during a $40{ }^{\circ} \mathrm{C} / \mathrm{min}$ cooling. The simulations were conducted with the sets of parameters according to Table 2. terms of a thermodynamic extrapolation, overestimate the enthalpy in the ageing process and the SC model, which takes into account the possibility of not reaching the equilibrium, could provide a better description, especially for polymeric systems where topological constraints are important. So, an increase of $\delta / \Delta C_{p}\left(T_{\mathrm{g}}\right)$ with increasing crosslinking degree should be expected. In this case $\delta / \Delta C_{p}\left(T_{\mathrm{g}}\right)$ increases from 27 to $67 \%$ when the crosslinking degree increases from 0.5 to $5 \mathrm{wt} \%$ but then decreases again to $12 \%$ when the crosslinking degree is $9 \mathrm{wt} \%$. For PMMA9 the fittings are not as good as the ones corresponding to the other networks. Perhaps, PMMA9 is such a highly heterogeneous network that the SC model is not adequate to describe its behaviour and this could be the reason for the unexpected decrease of $\delta / \Delta C_{p}\left(T_{\mathrm{g}}\right)$ for PMMA9.

The temperature dependence of the relaxation time was calculated with the model equations for the cooling of the samples at $40{ }^{\circ} \mathrm{C} / \mathrm{min}$ from equilibrium, using the parameters of Table 2. These results are shown in Fig. 8.

In this figure it is seen the change from a VFTH-type behaviour (in the equilibrium state) to an Arrhenius-type behaviour in the glassy state for all the samples, as already observed for PET in a previous work [74]. The equilibrium relaxation times are higher for PMMA9 than for the other networks, reflecting the higher glass transition temperature of this network when compared with the other samples. The relaxation time curves for PMMA0.5, PMMA1 and PMMA5 are almost coincident. This finding is consistent with the close $T_{\mathrm{g}}$ values of these three materials.

\section{Conclusions}

The structural relaxation studies presented in this work enabled to investigate in detail the effect of crosslinking on the glass transition dynamics of PMMA. The modelling of the DSC scans by means of the SC model allowed to accede to a series of parameters characteristic of each sample and to calculate the relaxation times of the structural relaxation process from the experimental results obtained after different thermal histories. Based on the modelling results it was suggested the presence of crosslink heterogeneity in these systems.

The increase of crosslinker content from 0.5 to $9 \mathrm{wt} \%$ increased the calorimetric glass transition temperature $\sim 12{ }^{\circ} \mathrm{C}$, decreased the heat capacity increment and 
promoted a significant broadening of the glass transition of the PMMA networks. For all the networks and from the enthalpy loss calculations between the aged and unaged states it was possible to estimate a temperature interval in which the conformational rearrangements take place in the glassy state at a significant rate. This temperature interval increases as the crosslinking degree increases.

The effect of crosslinking density on the fragility of the PMMA networks was studied. The high values of the fragility index $m$ obtained for these systems (between 71 and 110) indicated that they are kinetically fragile systems. Moreover, it was found that $m$ increases with increasing crosslinking degree.

\section{Acknowledgements}

Financial support for this work was provided by FCT, through the POCTI and FEDER programmes (JFM and NMA) and by the Spanish Science and Technology Ministry through the MAT2003-05391-C03-01 project (JLGR). NMA wishes to acknowledge FCT for the financial support through the grant PRAXIS XXI/BD/20327/99.

\section{References}

[1] Hutchinson JM. Prog Polym Sci 1995;20:703.

[2] Hodge IM. J Non-Cryst Solids 1994;169:211.

[3] McKenna GB. J Res Natl Inst Stand Technol 1994;99:169.

[4] Narayanaswamy OS. J Am Ceram Soc 1971;54:491.

[5] Moynihan CT, Macedo PB, Montrose CJ, Gupta PK, DeBolt MA, Dill JF, Dom BE, Drake PW, Esteal AJ, Elterman PB, Moeller RP, Sasabe H. Ann N Y Acad Sci 1976;279:15.

[6] Kovacs AJ, Aklonis JJ, Hutchinson JM, Ramos AR. J Polym Sci, Polym Phys Ed 1979;17:1097.

[7] Scherer GW. J Am Ceram Soc 1984;67:504.

[8] Hodge IM. Macromolecules 1987;20:2897.

[9] Scherer GW. J Non-Cryst Solids 1990;123:75.

[10] Gomez Ribelles JL, Monleon Pradas M. Macromolecules 1995;28:5867.

[11] Gomez Ribelles JL, Monleon Pradas M, Vidaurre Garayo A, Romero Colomer F, Más Estellés J, Meseguer Dueñas JM. Polymer 1997;38: 963.

[12] Williams G, Watts DC. Trans Faraday Soc 1970;66:80.

[13] Kovacs AJ, Aklonis JJ, Hutchinson JM, Ramos AR. J Polym Sci, Polym Phys Ed 1979;17:1097.

[14] Mijovic J, Nicolais L, D’Amore A, Kenny JM. Polym Eng Sci 1994; 34:381.

[15] Hutchinson JM, Montserrat S, Calventus Y, Cortés P. Macromolecules 2000;33:5252.

[16] Málek J. Macromolecules 1998;31:8312.

[17] Mascarell JB, Garcia-Belmonte G. J Chem Phys 2000;113:4965.

[18] Tribone JJ, O'Reilly JM, Greener J. Macromolecules 1986;19:1732.

[19] Gómez Ribelles JL, Ribes Greus A, Díaz Calleja R. Polymer 1990;31: 223.

[20] Prest WM, Roberts Jr FJ, Hodge IM. Proc 12th NATAS Conf 1980;119-23.

[21] Romero Colomer F, Gomez Ribelles JL. Polymer 1989;30:849.

[22] Tool AQ. J Am Ceram Soc 1946;29:240.

[23] Brunacci A, Cowie JMG, Ferguson R, Gómez Ribelles JL, Vidaurre Garayo A. Macromolecules 1996;29:7976.
[24] Meseguer Dueñas JM, Vidaurre Garayo A, Romero Colomer F, Más Estellés J, Gómez Ribelles JL, Monleón Pradas M. J Polym Sci, Polym Phys Ed 1997;35:2201.

[25] Montserrat Rivas S, Gómez Ribelles JL, Meseguer Dueñas JM. Polymer 1998;39:3801.

[26] Gómez Ribelles JL, Vidaurre A, Cowie JMG, Ferguson R, Harris S, McEwen IJ. Polymer 1998;40:183.

[27] Hernández Sánchez F, Meseguer Dueñas JM, Gómez Ribelles JL. J Therm Anal Cal 2003;72:631.

[28] Cowie JMG, Gómez Ribelles JL, Meseguer Dueñas JM, Romero FJ, Torregrosa C. Macromolecules 1999;32:4430.

[29] Gómez Ribelles JL, Monléon Pradas M, Vidaurre Garayo A, Romero Colomer F, Más Estelles J, Meseguer Dueñas JM. Macromolecules 1995;28:5878.

[30] Adams G, Gibbs JH. J Chem Phys 1965;43:139.

[31] Gibbs JH, DiMarzio EA. J Chem Phys 1958;28:373.

[32] Hourston DJ, Song M, Schafer FU, Pollock HM, Hammiche A. Polymer 1999;40:4769.

[33] Alcântara RM, Rodrigues AP, Barros GG. Polymer 1999;40:1651.

[34] Ioan S, Grigorescu G, Stanciu A. Polymer 2001;42:3633.

[35] Scott TF, Cook WD, Forsythe JS. Eur Polym J 2002;38705.

[36] Gómez Ribelles JL, Monléon Pradas M, Meseguer Dueñas JM, Torregrosa Cabanilles C. J Non-Cryst Solids 2002;307-310:731.

[37] Fried JD. In: Dawkins JV, editor. Developments in polymer characterization. Applied Science Series, vol. 4. London: Applied Science Publishers; 1983.

[38] Utracki LA. Polymer alloys and blends. Munich: Hanser; 1989.

[39] Oudhuis AACM, ten Brinke G. Macromolecules 1992;25:698.

[40] Gómez Ribelles JL, Meseguer Dueñas JM, Torregrosa Cabanilles C, Monleón Pradas M. J Phys: Condens Matter 2003;15:S1149.

[41] Ellis TS, Karasz FE, Brinke GT. J Appl Polym Sci 1983;28:23

[42] Cook WD, Meharabi M, Edward GH. Polymer 1999;40:1209.

[43] Litovitz TA. J Chem Phys 1952;20:1088.

[44] Moynihan CT, Easteal AJ, deBolt MA, Tucker J. J Am Ceram Soc 1976;59:12.

[45] Ediger MD, Angel CA, Nagel SR. J Phys Chem 1996;100:13200

[46] Plazek DJ, Ngai KL. Macromolecules 1991;24:1222.

[47] Roland CM, Ngai KL. Macromolecules 1992;25:5765.

[48] Donth E. J Polym Sci Phys Ed 1996;34:2881.

[49] Alves NM, Gómez Ribelles JL, Gómez Tejedor JA, Mano JF. Macromolecules 2004:37:3735

[50] Robertson CG, Santangelo PG, Roland CM. J Non-Cryst Solids 2000; 275:153.

[51] Hempel E, Hempel G, Hensel A, Schick C, Donth E. J Phys Chem B 2000; 104:2460

[52] Saiter A, Devallencourt C, Saiter JM, Grenet J. Eur Polym J 2001;37: 1083.

[53] Huang D, McKenna GB. J Chem Phys 2001;114:5621.

[54] Montserrat S, Cortés P, Calventus Y, Hutchinson JM. J Polym Sci, Part B: Polym Phys 2000;38:456.

[55] Struik LCE. Physical ageing in amorphous polymers and other materials. Amsterdam: Elsevier Science; 1978.

[56] Montserrat S. Prog Colloid Polym Sci 1992;87:78.

[57] Hempel E, Beiner M, Horing S, Donth E. Colloid Polym Sci 1995; 273:1151.

[58] Cowie JMG, Ferguson R. Polymer 1993;34:2135.

[59] Takahara K, Saito H, Inoue T. Polymer 1999;40:3729.

[60] Nanzai Y, Miwa A, Cui SZ. Polym J 2000;32:51.

[61] Brinke GT, Grooten R. Colloid Polym Sci 1989;267:992.

[62] Bauwens-Crowet C, Bauwens JC. Polymer 1986;27:709.

[63] Mathot VBF. Polymer 1984;25:579.

[64] Matsuo ES, Orkisz M, Sun ST, Li Y, Tanaka T. Macromolecules 1994;27:6791

[65] Mallan S, Horkay F, Hecht AM, Geissler E. Macromolecules 1989;22: 3356.

[66] Gurtovenko AA, Gotlib YY. J Chem Phys 2001;115:6785.

[67] Schellenberg J, Hamann B. Polym Bull 1993;31:479. 
[68] Nie JJ, Du BY, Oppermann W. Macromolecules 2004;37:6558.

[69] Kara S, Pekcan O. Mater Chem Phys 2003;80:555.

[70] Norisuye T, Tran-Cong-Miyata Q, Shibayama M. Macromolecules 2004;37:2944.

[71] Kannurpatti AR, Anderson KJ, Bowman CN. J Polym Sci, Part B: Polym Phys 1997;35:2297.

[72] Ellis TS. Macromolecules 1990;23:1494.
[73] Cameron N, Cowie JMG, Ferguson R, Gómez Ribelles JL, Más Estelles J. Eur Polym J 2002;38:597.

[74] Alves NM, Mano JF, Balaguer E, Meseguer Dueñas JM, Gómez Ribelles JL. Polymer 2002;43:4111.

[75] Andreozzi L, Faetti M, Giordano M, Palazzuoli D. Macromolecules 2002;35:9049. 